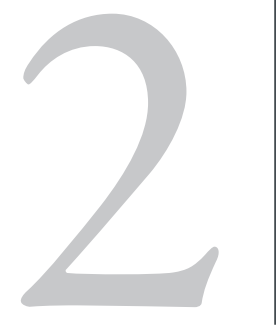

\title{
ARQUITETURA DA PARTICIPAÇÃO SOCIAL NO BRASIL: UM ESPAÇO EM CONSTRUÇÃO
}

\author{
ARCHITECTURE OF SOCIAL \\ PARTICIPATION IN BRAZIL:A FIELD \\ UNDER CONSTRUCTION
}

\author{
Luiza Reis Teixeira ${ }^{1}$ \\ Marco Antonio Carvalho Teixeira ${ }^{2}$
}

Recebido: $15 / 03 / 2019$

Aceito: 05/06/2019

\section{RE S U M E N}

A incorporação de cidadãos na esfera pública emergiu como uma inovação democrática, que fez surgir diversas instituições, nas mais diferentes realidades. Vários sistemas democráticos no mundo começaram a desenvolver espaços institucionais para a participação de cidadãos. Embora diferentes, as Instituições Participativas (IPs) tornaram-se uma realidade em diversos países e trouxeram a promessa da democracia com maior capacidade distributiva. No Brasil, o processo foi institucionalizado nos três níveis da federação e em várias áreas temáticas. Apesar da diversidade de enfoques nas investigações sobre a participação, a pesquisa empírica sobre os seus efeitos ainda é escassa. O objetivo deste trabalho é apresentar e discutir a arquitetura de participação social no Brasil, apontando lacunas nas relações estabelecidas com as instituições tradicionais da democracia.

P A L A V R A S - C H A V E : Inovação Democrática, Participação Social, Instituições Participativas, Arquitetura da Participação Social.

1. Universidade Estadual de Santa Cruz. Ilhéus (Bahia), Brasil. Contato: luizareisteixeira@gmail.com.

2. Fundação Getulio Vargas. São Paulo, Brasil. Contato: marco.teixeira@fgv.br. 


\section{A B S T R A C T}

The incorporation of citizens in the public sphere emerged as a democratic innovation, which gave rise to several institutions, in different environments. Several democratic systems in the world have begun to develop institutional spaces for citizen participation. Although different, Participatory Institutions (PIs) have become a reality in several countries and have brought the promise of a democracy with greater distributive capacity. In Brazil, the process was institutionalized in the three levels of the federation and in several thematic areas. Despite the diversity of approaches in participatory research, empirical research on its effects is scarce. The objective of this paper is to present and discuss the architecture of social participation in Brazil, pointing out the gaps in relations established with traditional institutions of democracy.

K E Y W O R D : Democratic Innovation, Public Participation, Participatory Institutions Architecture of Social Participation.

\section{N T R O D U Ç Ã O}

Das recentes transformações pelas quais a democracia tem passado, dois aspectos são relevantes para compreensão da participação social no Brasil. O primeiro refere-se ao fato da democracia ter se tornado uma aspiração universal, representando uma forma de governo ideal a ser alcançada nos mais diversos países no mundo e clamada por suas populações. Desde a chamada Terceira Onda de Democratização (Huntington, 1991), apenas alguns países de regiões em desenvolvimento permaneceram não democráticos.

O segundo aspecto refere-se ao que Lavalle (2011: 111) chamou de "plurarização institucional da democracia", para explicar as instituições surgidas no plano do governo representativo que passaram a incluir, de diferentes formas, a participação do cidadão. Para o autor, estas mudanças envolvem a proliferação de canais extraparlamentares de representação formal e informal, situados fora das fronteiras tradicionais do governo representativo, que desempenham funções distintas de experiências anteriores na doutrina democrática liberal (Lavalle, 2011).

A incorporação de instituições com a participação de cidadãos na esfera pública, é considerada por diferentes autores uma inovação democrática (Lavalle, 2011; Wampler, 2012; Saward; 2003; Smith, 2005; Michels, 2011; Geisel, 2012), que trouxe à tona uma diversidade de novas instituições em diferentes contextos e realidades. O surgimento dessas instituições esteve amparado na percepção de que a democracia representativa, por si só, não conseguiria melhorar o desempenho do Estado (Wampler, 2012). 
Todavia, na teoria democrática, o papel da participação do cidadão nunca foi uma categoria analítica de grande destaque, sendo esta discutida apenas, entre democratas participativos e deliberativos (Michels, 2011). Lavalle (2011b) destaca que, no Brasil, a categoria participação não vem a ser uma categoria analítica da teoria democrática, e que a ideia de participação entrou no cenário nacional como uma categoria prática, que teria sido mobilizada para dar sentido à ação coletiva praticada por atores populares. Logo, a partir da reflexão acerca de experiências participativas foram elaborados novos modelos teóricos de democracia que "ampliam os atores, os espaços e os sentidos da política" (Luchman, 2012: 59). Esses modelos questionam os pressupostos democráticos que restringem a ação política a determinados atores e estruturas institucionais, como únicos agentes capazes, relegando toda a pluralidade e complexidade social existente (Luchman, 2012).

Apresentamos nesse artigo uma análise das experiências de participação social no Brasil, por meio da sua arquitetura de funcionamento, em um nível macro, uma vez que são privilegiadas as condições estruturais, ou uma visão de sistema (Vera, 2012). Nesse sentido, são analisados os tipos de instituições participativas em funcionamento, os níveis de governo em que estão presentes, assim como as relações estabelecidas com outras instituições democráticas. Os conselhos de políticas públicas e as conferências são analisados, de forma mais aprofundada, no sentido de se pensar a arquitetura institucional de participação social. A escolha dos conselhos e conferências para análise, deve-se ao fato dos dois reunirem, ao mesmo tempo, números expressivos em relação à quantidade de pessoas envolvidas, nos últimos anos, e também, devido ao fato de reunirem a maior quantidade de estudos e pesquisas, quando comparadas às outras instituições.

Logo, o objetivo do artigo consiste em apresentar e discutir a chamada arquitetura institucional da participação social no Brasil, descrevendo sua estrutura de funcionamento e relações estabelecidas com outras instituições, a partir da análise dos conselhos e conferências. O artigo está organizado da seguinte forma: primeiramente, o conceito de inovação democrática é apresentado; e em seguida, são apresentadas as origens das instituições participativas no Brasil, de forma a mostrar sua evolução até o momento atual, descrevendo as principais características de sua arquitetura. Em seguida, são apresentadas as duas experiências mais emblemáticas de participação no Brasil, os conselhos de políticas públicas e as conferências, a partir do seu histórico e funcionamento atual. Por fim, são analisadas as relações estabelecidas com outras instituições democráticas, e alguns apontamentos sobre como pensar a arquitetura institucional de participação social no Brasil. 


\section{NOVAÇÕ E S D EMOCRÁT I C A S}

Saward (2003) ressalta que a história da democracia é repleta de inovações, que foram intensificadas com a chegada do século XXI. As inovações mais recentes tiveram origem com o fim da Guerra Fria, momento em que a maior parte dos países passou a se questionar como a democracia deveria ser e que significado deveria ter (Saward, 2003). A partir de 1960, as democracias mais tradicionais do hemisfério norte passaram a adotar formas de participação cidadã direta, como o plebiscito, o referendo, ou mesmo a iniciativa popular (Lavalle, 2011). A partir de 1990, diversos sistemas democráticos existentes, em diferentes regiões e localidades, passaram a inserir novas instituições envolvendo a participação de cidadãos na esfera pública. Em 2005, o relatório de pesquisa da Power Inquiry ${ }^{3}$, comissão da Câmara dos Lordes britânica, estabelecida para investigar as razões para o declínio da participação na política formal na Inglaterra, descreveu 57 experiências de inovação democrática em diferentes países, e analisou algumas delas de forma mais aprofundada (Smith, 2005).

Essas inovações foram divididas em seis tipos diferentes, entre elas: as inovações eleitorais, com objetivo de aumentar a participação da população, como o voto eletrônico e o voto por correspondência; as inovações consultivas, com objetivo de informar aos gestores públicos a visão dos cidadãos sobre determinado tema, como audiências públicas, grupos focais e mesas de diálogo; as inovações deliberativas, com objetivo de deliberar sobre políticas públicas e influenciar gestores públicos, como juris populares, conferências e dias deliberativos; as inovações de co-governança, com objetivo de conferir influencia expressiva aos cidadãos no processo de tomada de decisões, como o orçamento participativo e conselhos de juventude; as inovações de democracia direta, com objetivo de dar aos cidadãos o poder na tomada de decisão em assuntos estratégicos, como referendos e recalls; e, por fim, as inovações de democracia eletrônica, com objetivo de usar tecnologias de informação para envolver cidadãos no processo de tomada de decisão, como as consultas eletrônicas e comunicação com parlamentares (Smith, 2005).

3. A Power Inquiry foi formada em 2004, como o projeto centenário de dois dos fundos de Joseph Rowntree, empresário e político dedicado à redução da pobreza e outras mazelas sociais de sua época. Em 1904, o empresário utilizou parte de sua riqueza para a criação de três fundos independentes voltados para diferentes aspectos dos problemas sociais contemporâneos (Disponivel em: http://www.josephrowntree.org.uk/. Acesso em: 10 de novembro de 2015). 
Resultados dessas inovações democráticas, as Instituições Participativas (IPs), ocorrem em diferentes contextos, apresentam características diversas, e são inseridas em diferentes estruturas de funcionamento, isto é, em diferentes arquiteturas, e, é possível afirmar que tornaram-se uma realidade em diversos países do mundo. A participação social tem como ponto de partida a insatisfação com os resultados produzidos pelas instituições da democracia representativa, assim, o desenvolvimento de instituições que consultam a sociedade, ou a colocam como parte das políticas públicas, tende a carregar a promessa da promoção de uma democracia mais justa e com maior capacidade distributiva. Entretanto, é preciso atentar para o fato de que a participação pública pode ser usada para diferentes propósitos e objetivos, uma vez que, pode ser vista tanto como um elemento de sucesso da democracia, ou como um meio para alcançar algo mais, seja o resultado de uma decisão, ou o desejo de uma tomada de decisão mais informada, passível de verificação, e legítima (Abelson, 2006).

Milani (2008) ressalta que foi a partir dos anos 1990 que a dimensão da participação social passou a ser um dos "princípios organizativos centrais" (Milani, 2008: 42) dos processos de deliberação democrática, declarada e repetida em foros regionais e internacionais. $\mathrm{O}$ aumento da participação do cidadão tornou-se, então, prioridade oficial em diversos países, mesmo que, muitas vezes, se aproximasse mais de um discurso retórico, nem sempre posto em prática (Smith, 2005). Este "princípio participativo", construído com base em fontes diversas, passou a ser apoiado por atores diversos, como Banco Mundial, OCDE, União Europeia, Nações Unidas, assim como por diversas Organizações da Sociedade Civil, entre outros (Milani, 2008).

\section{PART I C I PAÇÃ O S O C IAL NO BRAS IL}

A partir do anos 1990, com a redemocratização, o Brasil se tornou um grande laboratório de experiências participativas, um dos países com maior número de práticas (Avritzer, 2008), e consequentemente, com uma complexa ecologia de relações entre Estado e sociedade (Pires, 2012). A incorporação de cidadãos e organizações da sociedade civil na esfera pública se institucionalizou nos três níveis da federação brasileira e também em diversas áreas temáticas. Até 2018, as instituições participativas estiveram instituídas como elementos característicos da gestão pública brasileira. Em 2014, havia, aproximadamente, 60.600 conselhos gestores de políticas públicas (Brasil, 2014), espalhados pelos 5.565 municípios brasileiros, totalizando mais de 500.000 conselheiros (Boullosa, 2014). Estima-se que as 74 conferências, das mais diversas áreas temáticas, ocorridas entre, 2003 e 2010, 
envolveram mais de 5 milhões de pessoas ao longo de suas etapas (Teixeira, 2012). Outras IPs, como audiências públicas, mesas de diálogo, também envolveram um grande número de pessoas em diferentes áreas temáticas, entre 2004 e 2018.

É possível afirmar que a formalização da participação social no Brasil se deu com a promulgação da Constituição Federal de 1988, embora tenham havido antecedentes históricos que fomentaram essa formalização, ocorrida durante a Constituinte. A chamada Constituição Cidadã, acabou absorvendo grande parte das reinvindicações do movimento de Participação Popular na Constituinte e institucionalizando diversas formas de participação da sociedade na gestão pública (Silva, 2008). Aproximadamente 30 artigos da Constituição expressam preceitos que incentivaram o desenvolvimento de instâncias participativas (Teixeira, 2011). Os princípios e diretrizes referentes à participação traçados pela Constituição estão relacionados a quatro aspectos, dispersos em alguns artigos constitucionais: 1. A cidadania como fundamento do Estado democrático; 2. Os deveres sociais em questões coletivas; 3. O exercício da soberania popular; 4. A participação social como forma de gestão pública.

- A cidadania como fundamento do Estado democrático (artigos $1^{\circ}$, $5^{\circ}, 8^{\circ}, 15$ e 17$)$;

- Os deveres sociais em questões coletivas (artigos 205, 216, 225, 227 e 230);

- O exercício da soberania popular (artigos 14 27, 29, 58 e 61);

- A participação social como forma de gestão pública (artigos 10, 18, 37, 74, 173, 187 e 231) (Teixeira, 2011: 3).

Outro aspecto da institucionalização de instituições participativas pela gestão pública também impulsionado pela Constituição de 1988 é a descentralização administrativa com gestão participativa, em especial, na saúde (art. 198), na seguridade social (art. 194), na assistência social (art. 203) e na educação (art. 206) (Teixeira, 2012).

Dois outros importantes fatores merecem destaque ao se pensar na institucionalização de instituições participativas no Brasil. O primeiro refere-se ao papel desempenhado por movimentos sociais, seja pela participação no momento da Assembleia Nacional Constituinte, como num momento posterior, ao pressionar para a criação de instâncias de cogestão de políticas públicas em áreas como a saúde, planejamento urbano, meio ambiente e assistência social, entre outras (Avritzer, 2013). O outro aspecto importante foi a chegada do Partido dos Trabalhadores ao poder, primeiramente em nível local, e, em seguida, no governo federal. No plano local, a principal 
contribuição ocorreu em 1988, com a eleição de Olívio Dutra para a prefeitura de Porto Alegre, e o início do Orçamento Participativo (OP) (Avritzer, 2013). Segundo Avritzer (2013: 12), o OP é:

(...) uma politica participativa local, que gera um processo de deliberação entre sociedade civil e Estado no nível local. Ele inclui atores sociais, membros de associações de bairro e cidadãos comuns em um processo de negociação e deliberação que acontece em duas etapas: uma etapa participativa, em que a participação é direta, e uma etapa representativa, na qual a participação ocorre por meio da eleição de delegados e ou conselheiros.

O OP tornou-se uma marca registrada das gestões do Partido dos Trabalhadores (PT) (Avritzer, 2013) e uma das instituições participativas mais conhecidas internacionalmente (Smith, 2013; Barrera, 2014; Heller, 2001), devido ao sucesso da experiência de Porto Alegre, que durou cerca de 15 anos, de 1990 a 2005 (Avritzer, 2008) ${ }^{4}$. Porto de Oliveira (2012) destaca que o OP, se tornou o fio condutor das experiências de políticas participativas, tendo ganhado reconhecimento internacional e prestígio rapidamente, chegando a ter contornos de mito, ou seja, experiência ideal de participação. Ainda nos anos 1990, a experiência se difundiu por cerca de 200 municípios brasileiros. A partir dos anos 2000 as experiências de OP se difundiram internacionalmente, totalizando 1.400 experiências ao redor do mundo, sendo a maior parte concentrada entre Europa e América Latina (Porto de Oliveira, 2012).

No plano nacional, a chegada de Lula ao governo federal, em 2003, gerou expectativas pela trajetória histórica de proximidade do Partido dos Trabalhadores (PT) com movimentos sociais e organizações da sociedade civil que atuaram no processo da redemocratização. Para Teixeira (2012), o governo Lula herdou um conjunto expressivo de espaços participativos, principalmente os conselhos e as conferências nacionais, que foram resultados do momento Constituinte de 1988, quando os princípios da descentralização e da participação foram difundidos. Portanto, é importante analisar como o governo Lula lidou com esse passado participativo.

Lula, no início do seu mandato, assumiu o compromisso de estabelecer um novo padrão de relacionamento entre sociedade civil e governo, com base no diálogo e na participação (Santos, 2014). A partir de 2003, o Governo Federal atribuiu à Secretaria Geral da Presidência da República (SGPR) o 
papel de interlocução do governo com a sociedade, e, por meio dela, desenvolveu ações para a ampliação da participação social (Teixeira, 2012). Essa secretaria foi dividida em três departamentos - Diálogos Sociais, Participação Social e Educação Popular e Mobilização Cidadã (Santos, 2014). A Secretaria Geral da Presidência teve como principais desafios, num primeiro momento, estimular a cultura da participação social no interior do governo e fornecer conceitos, orientações e procedimentos para promover o diálogo com movimentos sociais e organizações da sociedade civil (SANTOS, 2014). É possível afirmar que, durante este governo, as instituições participativas foram revitalizadas, ou mesmo desenvolvidas, mas pouco se pensou em sua estrutura de funcionamento nas esferas federativas e sua relação com outras instituições democráticas, isto é, sua arquitetura institucional.

O primeiro governo Dilma, iniciado em 2010, atribuiu a SGPR o desafio de articular os processos participativos e de promover a sinergia entre os órgãos da administração pública federal. Com isso, iniciou-se dentro do governo, a elaboração da Política Nacional de Participação Social (PNPS) e do Compromisso Nacional pela Participação Social (Santos, 2014). Submetida à consulta pública virtual, a PNPS tinha como objetivo fortalecer os mecanismos e as instâncias de participação social e diálogo entre o governo federal e a sociedade civil, definindo princípios e diretrizes a serem seguidos por órgãos do governo federal (SGPR, 2013), e o Compromisso tinha como objetivo orientar o estabelecimento de diretrizes para a articulação federativa e a promoção da participação social como método de governo (Santos, 2014). Em 23 de maio de 2014, a presidente assinou, por meio de decreto, a instituição da PNPS e do Sistema Nacional de Participação Social. Após diversas reações contrárias, na mídia, manifestadas por juristas e líderes da oposição, o decreto foi anulado pelo Congresso. Apesar de alardeado pela oposição como responsável pela criação de um poder paralelo ao parlamento, o texto da PNPS, de fato, não apresentou alterações significativas nas instituições participativas já existentes, apenas diretrizes para o funcionamento dos processos participativos. Para a esta pesquisa, por exemplo, pouco contribuiu na tarefa de pensar a arquitetura institucional de participação no Brasil, pois, embora mencione que deve existir "complementariedade, transversalidade e integração entre mecanismos e instâncias da democracia representativa, participativa e direta" (Brasil, 2014: Art. $3^{\circ}$ ), não especifica como deve ocorrer.

Ainda assim, é importante reconhecer que, a partir do governo Lula, a participação social começou a ser pensada e articulada de forma mais ampla, e, o que levou à consolidação de diversos tipos de instâncias participativas, em diferentes áreas setoriais de políticas públicas, nos três níveis da federação. Sobre a atual configuração das IPs no Brasil, Vera (2012) afirma que o 
panorama das instâncias de participação local parece uma selva institucional, com multiplicação de espaços de orientação subsetorial e trans-setorial. $\mathrm{O}$ autor destaca que, por conta dessa diversidade institucional de experiências participativas e pela ausência de ferramentas analíticas que tornem as experiências comparáveis, as estratégias de análise concentram-se em estudos de caso. Com isso, a apreensão do que Avritzer (2011) chamou de sistema de participação, e Vera (2012) de arquitetura de participação, torna-se uma tarefa árida.

Para Lavalle (2011), a aferição de efeitos da participação é uma tarefa complexa, uma vez que sequer existem consensos quanto aos efeitos esperados pela participação, ou pela relevância de analisá-las pelos seus efeitos. Para o autor, há um forte descompasso entre a riqueza das experiências participativas no Brasil e a precariedade do conhecimento gerado sobre seus efeitos.

A despeito dos avanços registrados no debate, as caracterizações minuciosas de casos (...), ainda não cederam passo a estudos avaliativos de fôlego. (...) a maior parte da literatura tem se concentrado em um tipo especifico de IP; isto é, a literatura tem assumido o formato das IPs como delimitação natural dos objetos cognoscíveis. Contudo, há pelo menos três ondas de IPs no Brasil - orçamentos participativos (OPs), conselhos e conferências, para não falar em Planos Diretores e Planos Plurianuais (PPAs)-, além de uma miríade de instâncias participativas, cujos efeitos poderiam ser avaliados se partindo de definições conceituais e metodológicas comuns (Lavalle, 2011: 36).

Portanto, tendo em vista os dados disponíveis e o conhecimento produzido a respeito, pensar na estrutura de funcionamento das IPs no Brasil e suas eventuais articulações, de forma mais ampla, se constitui em um desafio. Concordamos com Vera (2012) em considerar importante o avanço na caracterização das arquiteturas, pois, além de contribuir para a compreensão e explicação das IPs, é possível pensar em desenhos que alcancem melhores resultados. Para o autor, há uma grande distância entre a "apreensão qualitativa de uma inovação institucional específica, sua descrição formal ou arquitetônica e a eventual reconstrução de regimes de controle democrático" (Vera, 2012: 108). 


\section{CONSELHOS D E POLITTCA S P ÚB L I C A E D E D I RE I TOS}

A origem dos conselhos gestores está relacionada aos conselhos municipais de educação, no século XIX; como também, aos órgãos administrativos colegiados (Caixas e Institutos de Aposentadoria e Pensões), na área da previdência social, nas décadas de 20 e 30, do século XX. Contudo, foram os conselhos de saúde, criados em 1990, que se tornaram o paradigma inspirador do desenvolvimento dos conselhos mais recentes da democracia brasileira (Cortes, 2011). Para Teixeira (2012: 51), os conselhos gestores "são fruto da institucionalização dos conselhos populares experimentados no Brasil a partir da década de 1980". Também são tidos como uma conquista dos movimentos sociais pela democratização do Estado brasileiro (SGPR, 2011). Embora o princípio da participação esteja presente na Constituição de 1988, foram as legislações setoriais específicas, inicialmente, nas áreas de saúde, assistência social, trabalho e meio ambiente, que colocaram em prática esta participação, por meio de conselhos (SGPR, 2011). A partir da década de 1990, os conselhos de políticas públicas e de direitos se multiplicaram pelos municípios do país, uma vez que as transferências de recursos financeiros federais para os níveis subnacionais de governo, principalmente nas políticas sociais, passaram a ser condicionadas, entre outros requisitos, à existência destes fóruns participativos (Teixeira, 2012). Atualmente, existem conselhos para tratar de assuntos ligados a temas diversos, desde os mais tradicionais, como educação, saúde, assistência social, meio ambiente, planejamento urbano, segurança pública, a temas mais específicos, como o combate a drogas, turismo, atenção à pessoa com deficiência, entre outros. Os conselhos são formados por representantes de organizações sociais e do Poder Público, e têm o objetivo de promover a participação da sociedade civil na formulação, implementação, monitoramento e avaliação das políticas públicas (SGPR, 2011). A maneira como esses espaços funcionam varia de acordo com o contexto de institucionalização do conselho, a forma de organização social estabelecida, a definição do papel e dos objetivos e a delimitação da sua competência e das suas atribuições (Teixeira, 2012). Ou seja, embora tenham muitas similaridades entre si, os conselhos podem apresentar diferentes regras de funcionamento, uma vez que são regidos por diferentes leis e regulações.

Entre as semelhanças, podemos citar o fato dos conselhos funcionarem por meio de reuniões periódicas e pautas definidas; todos debatem temas relacionados às políticas e realizam o acompanhamento e a fiscalização da gestão de uma política pública; são espaços participativos, podendo ser consultivos ou deliberativos; são compostos por representantes do poder 
público e da sociedade civil, em geral, dividida em diferentes segmentos. É importante destacar que os conselhos não são abertos à participação de qualquer pessoa interessada na discussão, uma vez que os seus representantes são eleitos ou indicados, podendo haver a participação de conselheiros especialistas e de pessoas reconhecidas como importantes para determinado debate, muito embora estes não tenham poder de voto (Teixeira, 2012).

Mesmo que os conselhos tenham surgido, no Brasil, muito antes da redemocratização, foi a partir de 2003, que vários novos conselhos nacionais foram implantados, alguns já existentes passaram a contar com a participação de representantes da sociedade civil, e outros, que não estavam em funcionamento, foram reativados (SGPR, 2011). Em 2014, existiam 50 conselhos nacionais, em funcionamento no país, com a participação da sociedade civil, dos quais metade foi criada entre os anos de 2000 e 2009 (Brasil, 2014).

No plano municipal, o Brasil possui milhares de conselhos atuantes nas mais diversas áreas: saúde, educação, assistência social, infância e adolescência, segurança alimentar e nutricional, trabalho, alimentação escolar, entre outros. Atualmente, nenhum setor de política pública existe sem um conselho gestor (Boullosa, 2014). O número de conselheiros, a maioria com atuação voluntária, supera o número de vereadores eleitos (Farias, 2008), cerca de 500 mil por todo o país (Boullosa, 2014). Número esse que não para de crescer. Segundo a publicação oficial mais recente, que sistematizou os dados dos conselhos, a partir da base do Munic (IBGE), em 2014, existiam 62.562 conselhos municipais no Brasil (Brasil, 2014).

Portanto, uma primeira análise de estrutura de funcionamento dos conselhos gestores apresenta certa complexidade. Verticalmente, os conselhos estão disseminados nas três esferas da federação, embora não haja uma previsão formal de relação entre os conselhos das diferentes esferas. E, horizontalmente, existem diversos conselhos para diversas áreas temáticas. Se dividirmos o número de conselhos existentes pela quantidade de municípios brasileiros, chegamos a quantidade aproximada, de 11 conselhos por município. Pode parecer um número mediano para médios e grandes municípios, mas, levando em conta que mais de $70 \%$ do país é formado por municípios com população abaixo de 20 mil habitantes, acaba sendo um esforço considerável para municípios pequenos manter essa quantidade de conselhos em pleno funcionamento e com efetiva participação da sociedade.

Em geral, os conselhos não têm relações entre si formalmente previstas. Cada conselho é voltado para apoiar ou fiscalizar uma área temática, seja a alimentação escolar, ou saúde e estabelece relações com os atores partici- 
pantes da política pública em questão. Na área da educação, pais e professores são chamados a participar dos conselhos, já na área da saúde, usuários do sistema e representantes dos profissionais de saúde. Logo, cada área temática de conselho envolve um campo de discussão particular e segue as regras determinadas pela política pública. O Quadro 2 nos ajuda a visualizar os primeiros contornos da arquitetura institucional dos conselhos.

\section{QUADRO 1}

\section{CONSELHOS POR ESFERA DA FEDERAÇÃO}

\section{E ÁREAS TEMÁtICAS}

\begin{tabular}{|c|c|c|}
\hline ESFERA & QUANTIDADE & ÁREAS TEMÁTICAS \\
\hline FEDERAL & 50 Conselhos Nacionais (Brasil, 2014) & \multirow{3}{*}{$\begin{array}{l}\text { Política Urbana; Bem-estar Social; Educação; } \\
\text { Saúde; Meio ambiente; } \\
\text { Esporte; Moradia; Cultura; Transporte; Segurança } \\
\text { Pública; Saneamento Básico; Segurança Alimentar } \\
\text { e Nutrição; Direitos Humanos; Igualdade Racial; } \\
\text { Direitos da Criança e do Adolescente; Direito } \\
\text { das Mulheres; Direito dos Idosos; Direitos LGBT; } \\
\text { Direito dos Jovens; Direito das Pessoas com } \\
\text { Necessidades Especiais; Trabalho; Turismo; } \\
\text { Orçamento; Promoção do Desenvolvimento Social } \\
\text { e Econômico }\end{array}$} \\
\hline ESTADUAL & 650 Conselhos Estaduais (número estimado) & \\
\hline MUNICIPAL & 62.562 Conselhos Municipais (Brasil, 2014) & \\
\hline
\end{tabular}

O importante a se perceber, numa análise horizontal das relações estabelecidas entre conselhos e outras instituições democráticas, é o fato de que não há previsão de relacionamento com o poder legislativo, ou seja, com a câmara de vereadores, que por vezes sente seu poder ameaçado pelo conselho que desempenha uma atividade concorrente, ao aprovar a prestação de contas do executivo. Em geral, essa falta de articulação com outros poderes é percebida no funcionamento dos conselhos. Não há uma relação institucional formalizada entre os conselhos gestores e o poder legislativo. Ainda sobre as relações horizontais, é possível verificar uma estreita relação entre conselhos e conferências, em que, os conselheiros, muitas vezes são integrantes da comissão organizadora das conferências, ou participam como delegados.

Além da limitação apontada no que se refere à falta de previsão de relações institucionalizadas dos conselhos com outras instituições democráticas, 
Boullosa (2014) aponta uma série de limitações referentes a atuação dos conselhos municipais. Para a autora, há um ideal de que os conselhos deveriam simbolizar boas estratégias de governança, em um país democrático, mas com uma cultura política enraizada no patrimonialismo e clientelismo esse ideal é fragilizado. Contudo, o modelo corrente, leva a crer que o exercício do controle social desempenhado pelos conselhos é questionável, uma vez que seus mecanismos de accountability são frágeis, e eles estão subordinados à estrutura político-institucional do município.

\section{CONFEREN CIAS NACIONA IS}

A legislação brasileira instituiu as conferências, nas áreas de saúde e educação, em 1937, com a Lei número 378, de 13 de janeiro de 1937. As duas primeiras conferências realizadas no Brasil ocorreram em novembro de 1941, a Conferência Nacional de Educação e a Conferência Nacional de Saúde (Souza, 2013). Nessa época, o objetivo era ampliar o conhecimento do governo federal, em todo o país, sobre as atividades relacionadas à saúde e à educação, assim como, articular as iniciativas com a finalidade de aumentar a capacidade de execução dos programas governamentais, formando diretrizes mais claras em relação às atribuições e às relações entre os entes federados (Souza, 2013 citado por Horta, 2000; Hochman, 2005). Contudo, enquanto, no princípio, as conferências serviam aos propósitos da administração centralizada, com a reabertura política e redemocratização, na década de 1980, houve uma mudança progressiva do modelo dentro de uma lógica de descentralização e ampliação da participação social (Souza, 2013). Portanto, as conferências, assim como os conselhos, não representam uma nova experiência na história política brasileira, muito embora, apenas a partir de 1988, tenham-se tornado mais participativas e deliberativas; e, a partir de 2003, com o início do governo Lula, mais amplas, abrangentes, inclusivas e frequentes (Progrebinschi, 2010). Entretanto, para Avritzer (2013: 9), "mesmo tendo sido criadas na década de 1930, podem ser consideradas uma novidade na participação social no Brasil, pois relevam traços da dinâmica participativa em nível nacional". Como até 2002, as principais experiências de participação social no país (orçamento participativo, conselhos e planos diretores) ocorriam principalmente na esfera municipal, havia dúvidas sobre a possibilidade das experiências participativas alcançarem a esfera nacional (Avritzer, 2013).

A $8^{\text {a }}$ Conferência Nacional de Saúde, ocorrida em 1986, marcada por ampla participação popular, foi determinante para que, na Constituinte, fossem garantidas as bases do Sistema Único de Saúde (Teixeira, 2012). Souza (2013) 
destaca que as conferências de saúde dos anos 1980 e 90 renovaram uma invenção institucional e uma realização política de um governo autocrático, de modo participativo e democrático. A gestão participativa, um dos princípios do SUS, serviu de inspiração para outras áreas temáticas instituírem espaços participativos com o formato de conferências e conselhos nos três níveis da federação. A Assistência Social, por exemplo, instituiu as conferências como parte de um sistema de participação formalizado na lei 9.720, de 1993. Assim, as conferências passaram a ser usadas, nos últimos anos, como estratégia para promover o debate de determinados temas em todo o país, de forma estruturada, assim como, para aumentar a participação na formulação de políticas públicas em nível nacional (Teixeira, 2012). Segundo Pogrebinschi (2010), a partir de 2003, as conferências nacionais tornaram-se mais amplas por envolverem cada vez mais pessoas em suas diversas etapas que precedem ou funcionam de forma paralela, às nacionais, tais como, as etapas estaduais, municipais, regionais, temáticas, livres e virtuais. Tornaram-se mais abrangentes por tratar uma ampla variedade de áreas temáticas, visando atender aos diversos tipos de políticas públicas existentes. Atualmente, existem diversas áreas de realização de conferências, separadas por suas características singulares, mas unidas por uma transversalidade comum. Tornaram-se mais inclusivas, pois conseguiram inserir cada vez mais grupos da sociedade, tais como, ONGs, movimentos sociais, sindicatos, entidades empresariais, entre outros. E, o que é mais importante, tornaram-se mais frequentes, pois em suas diretrizes, muitas vezes, há a demanda pela convocação periódica (Pogrebinschi, 2010). Portanto, no contexto político democrático mais recente, as conferências de políticas públicas passaram a ocorrer em períodos regulares (a cada quatro, ou dois anos), com a participação de milhares de pessoas em todo o território nacional (Ciconello, 2012).

As conferências são, portanto, canais institucionais de participação social, com objetivo de promover, periodicamente, o diálogo entre Estado e sociedade acerca de determinado tema. As conferências nacionais são, na maior parte dos casos, convocadas pelo presidente da república, e são organizadas por órgãos do executivo, muitas vezes em parceria com conselhos das áreas afins (Ribeiro, 2013). O formato das conferências envolve um processo em etapas subsequentes (territoriais, municipais, regionais, estaduais e nacionais) e interconectadas (Brasil, 2014). As primeiras etapas, anteriores à etapa nacional, são momentos em que o debate se intensifica e se qualifica nos mais diversos temas e em contextos específicos. Também são formuladas propostas, consolidadas em relatórios que são encaminhados para as próximas fases. Entre as etapas municipais, regionais e estaduais, podem ocorrer conferências livres, temáticas, e virtuais, em geral, convocadas pela socie- 
dade civil. Ao longo das primeiras etapas, além do debate propositivo sobre a política, elegem-se delegados, representantes da sociedade e de governo, que conduzirão a discussão nas etapas posteriores (Ciconello, 2012). A conferência nacional representa a última etapa do processo, momento em que os representantes escolhidos debatem e elegem as propostas prioritárias.

Outro aspecto bastante relevante do funcionamento dos processos conferencistas está relacionado ao seu produto final: um documento contendo as resoluções, diretrizes e moções, que passaram pelo processo de elaboração e priorização pelos delegados de todas as etapas do processo conferencista, consolidados na etapa nacional. Portanto, ressalta-se como uma das virtudes do processo conferencista o envolvimento dos participantes na formação de consensos, além do fato de contribuírem para a elaboração de pautas políticas e de uma agenda de prioridades que deve influenciar a política pública em voga. Em geral, o acompanhamento do resultado das conferências é monitorado por organizações da sociedade civil em diversos espaços políticos, incluindo os conselhos (Ciconello, 2012).

No que se refere aos objetivos, a depender da área temática que a conferência se insere, eles podem variar entre formulação de propostas de políticas públicas, avaliação de ações e realidades, fortalecimento da participação ou mesmo, afirmação e difusão de ideias e compromissos. Consequentemente, os resultados também variam de acordo com os objetivos propostos (Ribeiro, 2013). Com isso, o documento final, produto da última etapa no processo conferencista, as conferências nacionais podem variar em formato, podendo conter, desde a criação ou reformulação e avaliação de um plano nacional de política, consolidado em eixos temáticos, diretrizes e objetivos; a estruturação ou avaliação de um sistema de política existente; relatórios síntese sobre o que foi debatido durante a conferência; ou mesmo, transcrições e deliberações das conferências, sem organização em formato de texto final (Ribeiro, 2013).

O objetivo maior na realização de uma conferência é que o conteúdo do documento final consiga influenciar políticas e ações implementadas pelo governo, ou mesmo se tornar um projeto de lei. Diversos projetos de lei, relacionados às deliberações de conferências foram aprovados pelo Congresso Nacional, ou colocados em prática pelo Executivo, por via administrativa (SGPR, 2011). Pogrebinschi (2010), em pesquisa sobre os impactos das conferências nacionais de políticas públicas sobre a atividade legislativa no Brasil, constatou que se constituem em um fenômeno novo e de grande potencial para o aprofundamento do exercício da democracia no Brasil. $\mathrm{O}$ resultado da pesquisa mostrou que as conferências têm influenciado ini- 
ciativas de proposições no Congresso Nacional, de maneira relativamente eficiente, "uma vez que diversas proposições aprovadas, além de emendas constitucionais promulgadas, são tematicamente pertinentes a diretrizes extraídas das diversas conferências" (Pogrebinschi, 2010: 84).

Os números relacionados às conferências são bastante expressivos. Aproximadamente 7 milhões de pessoas adultas participaram diretamente das conferências, em mais de 5 mil municípios, em todos os estados da federação (Avritzer, 2013; Brasil, 2014). A pesquisa, contudo não encontrou uma fonte de dados que reunisse informações sobre a quantidade de conferências municipais e estaduais já realizadas no país, o que demonstra que os níveis estaduais e municipais têm sido analisados em menor frequência. A abrangência de temas discutidos também merece destaque, 41 temas, das mais diversas áreas. Outra observação, possível de apreender a partir dos números, é que as conferências ganharam um grande impulso a partir de 2003, com o início do governo Lula. A seguir, o Quadro 2 sintetiza alguns dos números acerca da realização de conferências no Brasil.

\section{QUADRO 2}

\section{CONFERÊNCIAS NO BRASIL EM NÚMEROS}

\section{DADOS RELEVANTES}

141 conferências de 1941 a 2016 (Brasil, 2014; www.participa.br, 2016)

114 conferências entre 2003 e 2016 - 80 \% (Brasil, 2014; www.participa.br, 2016)

28 conferências, entre 2003 e 2012, realizadas pela primeira vez (Brasil, 2014)

De 34 ministérios, 22 envolveram-se na realização de ao menos uma conferência, 64\% dos órgãos (Brasil, 2014)

Aproximadamente 7 milhões de pessoas participaram, segundo estimativas que consideram apenas a população adulta do país (Avritzer, 2013)

Aproximadamente 5 mil municípios brasileiros envolvidos (Brasil, 2014)

Mais de 5.000 resoluções/ deliberações durante a etapa nacional, maioria referente a temas de competência do Governo Federal (Brasil, 2014)

$\mathbf{5 6 6}$ projetos de lei e $\mathbf{4 6}$ projetos de emenda à Constituição, apresentam ligação direta com as diretrizes das conferências (Souza, 2012).

Mais de $\mathbf{4 0}$ temas de políticas públicas - exemplos: desenvolvimento, geração de emprego e renda, inclusão social, saúde, educação, meio ambiente, direitos das mulheres, igualdade racial, reforma agrária, juventude, direitos humanos, ciência e tecnologia, comunicação, diversidade sexual, democratização da cultura, reforma urbana, segurança pública, entre muitas outros (SGPR, 2011). 
Além dos dados quantitativos, é importante observar que as conferências abordaram diversos temas que foram discutidos pela primeira vez com a sociedade. A realização das conferências, na maior parte das áreas temáticas, atendeu a reivindicações tradicionais de movimentos e atores sociais, como também representou o resgate de dívidas históricas com determinados setores da sociedade. Diversos exemplos podem ser citados, como o caso da Conferência Nacional de Gays, Lésbicas, Bissexuais, Travestis e Transexuais, que teve a segunda edição em abril de 2016; de Povos Indígenas (2006); de Políticas para as Mulheres (2004, 2007, 2011 e 2016); as Conferências Nacionais da Juventude (2008, 2011 e 2015); dos Direitos da Pessoa com Deficiência (2006, 2008, 2012 e 2016); de Promoção da Igualdade Racial (2005, 2009 e 2013); dos Direitos da Pessoa Idosa (2006, 2009, 2011 e 2016); entre outras (BRASIL, 2014).

A arquitetura institucional de funcionamento das conferências assemelha-se à arquitetura dos conselhos, seja verticalmente, ou horizontalmente. Verticalmente, já que ocorre nos três níveis da federação, com uma pequena diferença, pois nas conferências as etapas municipais devem preceder as estaduais, que, por sua vez, precedem as nacionais. Outra diferença em relação aos conselhos é o fato de que, simultaneamente às conferencias municipais e estaduais, podem ocorrer conferências regionais, livres, virtuais ou temáticas, extrapolando, assim, a organização federativa do país. No que se refere à análise da arquitetura no sentido horizontal, ou seja, das relações estabelecidas com instituições democráticas e outras IPs, também encontramos semelhanças entre conselhos e conferências. As conferências são frequentadas por atores sociais diversos vinculados à área temática da política pública sobre a qual a conferência versa, assim como por representantes do governo do poder executivo.

No que se refere a relações com outras IPs, as conferências apresentam uma grande aproximação com os conselhos nacionais, que, muitas vezes, organizam as conferências de sua área temática de atuação, e, quase sempre, participam. Souza (2013), em pesquisa conduzida pelo IPEA, que buscou mapear as características do desenho institucional dos processos conferencistas realizados entre 2003 e 2011, analisou 69 conferências consideradas típicas $^{5}$, e constatou que $40,6 \%$ dos processos conferencistas foram realizados em corresponsabilidade por mais de um órgão federal, ou por um

5. A pesquisa considerou conferências atipicas aquelas "que não possuiam uma ou mais das seguintes características: organização de responsabilidade de um órgão do Executivo ou de um conselho gestor; realização de etapas preparatórias; processos seletivos para escolha de representantes governamentais e não governamentais para a etapa nacional" (SOUZA, 2013, p 56). Com isso, 13 conferências das 83 realizadas no período de análise, 2003 a 2011 , foram consideradas atípicas e, portanto, não analisadas no estudo. 
órgão e o respectivo conselho gestor de política; e também, que 43,5\% dos processos tiveram o envolvimento do conselho na organização. A participação dos conselhos nas conferências é ainda mais alta: entre as conferências típicas, $84 \%$ tiveram a atuação de pelo menos um conselho.

Os conselhos podem atuar nas conferências seja tendo um papel central na organização das mesmas, quando, muitas vezes, é integrante das comissões organizadoras, ou apenas pela participação nas etapas da conferência (Souza, 2013). A depender da área temática, mais de um conselho pode participar de determinada conferência. Contudo, a relação entre conselhos e conferências não está prevista formalmente e, por isso, em alguns momentos, não fica claro qual deve ser a atuação do conselho em relação às deliberações da conferência. A relação das conferências com outras IPs também não está prevista formalmente, e, portanto, não há uma previsão de integração entre os dois, o que pode vir a ocorrer de forma espontânea, a depender da área temática.

Almeida (2013) aborda, também, a relação das conferências com a esfera formal do Estado, tanto o Poder Executivo, como a burocracia. Para a autora, há uma baixa articulação entre as instituições, uma vez que, formalmente, não há nada que garanta que as deliberações serão institucionalizadas por meio de políticas públicas, ou outras formas. Boa parte das deliberações aprovadas nas conferências demandam encaminhamento, de competência exclusiva do ministério responsável pela realização da conferência. Logo, em muitos casos, a real efetivação dos resultados de uma conferência pode depender da relevância que o tema tem na agenda pública. Como não há uma previsão sobre o acompanhamento dos resultados, não há uma definição de um método institucional de gestão, que seja responsável por atender às deliberações dentro da esfera pública federal, e, com isso, pode ocorrer um processo pouco efetivo e incerto. Ou seja, o esforço empreendido na realização do processo conferencista, em todas as suas etapas, pode ter suas deliberações engavetadas (Almeida, 2013).

Ainda sobre a falta de articulação formal entre conferências e Estado é possível citar a falta de instrumentos legais que garantam a convocação das mesmas. Em 60\% das conferências analisadas por Almeida (2013), não havia instrumentos legais que garantissem a continuidade. Ou seja, a mudança de governo pode implicar numa diminuição, ou interrupção na realização dos processos conferenciais no Brasil, uma vez que, na maior parte dos casos, o poder executivo é quem convoca a conferência. Se há pouca articulação formal na relação com o poder executivo, com o poder legislativo há ainda mais afastamento. Os representantes do legislativo participam 
das conferências quando suas bandeiras de luta são relacionadas ao tema da conferência, mas não há uma previsão formal de sua participação.

\section{ARQUITET URA DA PARTICIPAÇÃ O}

A análise da arquitetura da participação, ou do desenho institucional das instituições participativas vem, gradativamente, ganhando mais espaço na literatura sobre o tema (Fung, 2006; Avritzer, 2008; Lüchmann, 2008; Brasil, 2010; Faria, 2011; Pires, 2011; Teixeira, 2012). Avritzer (2008) afirma que a natureza do desenho participativo deverá ganhar, cada vez mais, influência para o sucesso de experiências participativas, e a escolha de um desenho adequado será determinante para a continuidade dessas experiências no futuro. Brasil (2013: 9) destaca que as características dos desenhos "podem favorecer ou prejudicar a qualidade dos processos participativos e deliberativos, bem como afetar a capacidade decisória e o funcionamento de tais canais". Ou seja, o desenho institucional pode levar a grandes limitações aos potenciais de participação deliberativa, mesmo em contextos em que a sociedade civil seja ativa, e haja algum grau de comprometimento político do governo com a promoção da participação. Desta forma, IPs podem ser reduzidas a um papel meramente ritualístico ou constrangidas por lógicas burocratizantes (Brasil, 2013).

Nesse sentido, apresentamos, uma comparação entre os conselhos de políticas públicas e os processos conferencistas, a partir de uma análise vertical, entre os diferentes níveis da federação e, também, uma análise horizontal, apresentando as relações entre IPs e outras instituições democráticas. No que se refere à sua estrutura vertical, conselhos e conferências apresentam um desenho similar, uma vez que ocorrem nos três níveis da federação. Contudo, nas conferências, as etapas municipais e estaduais funcionam como preparatórias da etapa nacional, o que significa que, verticalmente, há uma relação entre as conferências, o que não ocorre nos conselhos. Os conselhos, nos moldes atuais, são parte integrante de políticas públicas, e, em alguns casos, o repasse de determinados recursos, como para a merenda escolar, está vinculado à sua existência. Ou seja, enquanto as conferências dependem da vontade política do chefe do poder executivo para serem convocadas, os conselhos são fundamentais para o repasse de recursos. Por isso, municípios de menos de 20 mil habitantes chegam a ter em média 11 conselhos, mesmo com uma sociedade civil organizada reduzida para ocupar esses assentos. Na prática, algumas organizações mais tradicionais, como a internacional Rotary Club, acabam sendo convidadas para participar de conselhos, mesmo que não sejam reconhecidas por apresentar 
expertise no assunto, mas para ocupar a vaga destinada a sociedade civil.

No que se refere à análise horizontal, ou seja a relação estabelecida entre as duas IPs com outras instituições democráticas, entre si e também com o poder executivo e legislativo, há pouca previsão formal dessas relações. Os conselhos, especificamente, apresentam uma relação bastante formalizada com o poder executivo, uma vez que, como parte integrante de diversas políticas públicas, são instituídos e têm as condições de funcionamento garantidos por esse poder, assim como, em muitos casos, o repasse de recursos está atrelado à aprovação das contas do executivo pelo conselho. A mesma relação não ocorre com o poder legislativo. Mesmo que realizando uma função semelhante à do legislativo, na aprovação de contas, não há vagas, nos conselhos, para representantes do legislativo, e o poder legislativo, por sua vez, não tem instituído formalmente uma relação com os conselhos. O modelo ideal conferencista deve envolver os três poderes, por isso, acaba sendo comum mencionar que as delegações governamentais devem ser compostas por representantes dos três poderes, o que não ocorre, na maior parte dos casos. Conforme discutido na sessão anterior, as conferências são, em geral, convocadas pelo poder executivo e contam com a participação de seus representantes. Contudo, a relação com os poderes judiciários e legislativos são raras. Teixeira (2012) identificou três conferências que mencionaram vagas para o Judiciário, e cinco para o poder Legislativo. Além do pouco envolvimento dos dois poderes nas conferências, não há uma previsão formal de articulação entre eles, o que acaba influenciando diretamente a implementação das propostas formuladas.

O fato de o governo federal ter sido o principal promotor e financiador das principais IPs leva a uma institucionalização estatal da participação, uma vez que a promoção do controle social acabou sendo incorporada à agenda do Estado. Embora a estrutura da participação social seja muito ampla e diversa, o esforço empreendido pelo governo federal em estabelecer um Sistema Nacional de Participação Social não foi bem sucedido na delimitação das relações a serem estabelecidas pelas IPs com outras instituições democráticas. Os estudos e pesquisa sobre participação também não se voltam para apreensão das articulações a serem estabelecidas pelas IPs.

Apresentamos nesse artigo, uma análise das experiências de participação social no Brasil, através da sua arquitetura de funcionamento. A partir dos dados disponíveis, e do conhecimento produzido sobre o tema, nos propusemos a refletir sobre algumas representações gráficas para essa arquitetura. Acreditamos que o avanço na caracterização das arquiteturas, contribuem para a compreensão e explicação das IPs, como também possibilita 
pensar em desenhos de arquiteturas que alcancem melhores resultados.

Foi possível encontrar uma lacuna no que se refere à articulação, ou seja, as relações a serem estabelecidas pelas IPs com outras instituições democráticas. Tanto a análise dos conselhos quanto a das conferências apontaram para a falta de delimitação formal de articulação. Com isso, as relações vão sendo estabelecidas de acordo com os principais articuladores das temáticas, sejam representantes do governo, ou da sociedade civil. Acreditamos ser de grande importância deixar espaço para que relações sejam estabelecidas de forma espontânea, mas, em algumas situações, elas podem não ocorrer. Portanto, concordamos com Avritzer (2013:138) ao afirmar que a "efetividade das políticas participativas no plano nacional continuará dependente da implementação de arranjos capazes de integrar participação e gestão".

Concordamos com o argumento de que é importante fomentar a conexão entre as diferentes arenas deliberativas em um sistema mais amplo e formal de deliberação, uma vez que a articulação não é natural ou automática. A implementação das IPs no Brasil não veio acompanhada de uma estratégia de coordenação horizontal entre elas, ou mesmo de coordenação vertical entre as diferentes esferas de governo e de outras instituições democráticas. Conforme destaca Almeida (2013: 200) sobre as conferências, "os dados coletados até o momento dão conta de expressar a fragilidade da articulação com a população, com outras IPs e com o Estado". Acreditamos que a pesquisa sobre o tema deva avançar no sentido de desenvolver apontamentos sobre como desenhar fóruns mais permeáveis e mais conectados com as esferas formais e informais. E para avançar na proposição de desenhos de arquitetura, ampliar o escopo de estudo para além de orçamentos participativos, conselhos e conferências de políticas públicas, olhando também para outras IPs como, por exemplo, consultas públicas, audiências e ouvidorias.

Nesse sentido, ao desenhar arranjos de participação social é importante que seja pensada, de forma sistemática, a articulação com as instituições tradicionais da democracia representativa, uma vez que o poder legislativo é peça fundamental nos processos de planejamento e alocação de recursos para as políticas públicas (Silva, 2009). Contudo, a ampla difusão das IPs, ocorre em meio a uma profunda crise no sistema de representação política no Brasil. Assim, ao mesmo tempo em que são desenvolvidas novas instituições para inclusão da participação social na esfera pública, o sistema de representação encontra-se em crise de legitimidade, e não vem sendo capaz de se renovar ou sair dessa crise (Avritzer, 2013). 
Desde 2016, o campo da participação social vem enfrentando retrocessos. Segundo Pogrebinschi (2017: 3), desde o início da gestão do vice-presidente Michel Temer "a estrutura do que um dia se vislumbrou como um sistema nacional de participação social tem ruído em pedaços". Conselhos e Conferências sofrem com falta de recursos e tem sua continuidade fragilizada. Sobre as inovações democráticas na América Latina, que tradicionalmente, tem sido estimuladas pelo Estado, Pogrebinschi (2017: 5) alerta "a institucionalização pode garantir que as inovações participativas permaneçam no lugar, mas não podem assegurar que elas sejam sempre democráticas ou legítimas". 


\section{RE F E R E N C I A S}

Abelson, J. (2006). Assessing the Impacts of Public Participation: Concepts, Evidence and Policy Implications. In: Canadian Policy Research Networks. Réseaux canadiens de recherche en politiques publiques. Research Report PI06. Public Involvement Network.

Avritzer, L. (2013). Experiência Democrática, Sistema Político e Participação Popular. São Paulo: Editora Fundação Perseu Abramo. 1. ed., 128p.

Avritzer, L. (2008). Instituições participativas e desenho institucional. In: Opinião Pública (UNICAMP), v. 14, p. 43-64.

Barrera, Laura Beatriz Montes de Oca. (2014). ¿Innovaciones democráticas?: Análisis del Consejo Consultivo de telecomunicaciones en México. Revista Mexicana de Sociologia, Mexico D.F., v. 2, n. 76, p.287-320, abr.. Disponível em: http://www.scielo.org. $\mathrm{mx} / \mathrm{pdf} / \mathrm{rms} / \mathrm{v76n2/v76n2a5.pdf.} \mathrm{Acesso} \mathrm{em:} 14$ abr. 2016.

Boullosa, R. F.; Araújo, E. T.; Junqueira, Luciano. (2014). Os conselhos gestores municipais no Brasil: o paradoxo do bom moço que pode engessar processos de políticas públicas. In: $V$ Congreso Internacional en Gobierno, Administración y Politicas Públicas, Madrid. ANAIS do V Congreso Internacional en Gobierno, Administración y Políticas Públicas. Madrid: GIGAPP- IUIOG, 2014. v. 1. p. 1-16.

Brasil. Decreto $\mathrm{n}^{\circ}$ 8.243, de 23 de maio de 2014. Institui A Política Nacional de Participação Social - Pnps e O Sistema Nacional de Participação Social - Snps, e Dá Outras Providências. Brasília, Disponível em: <http://www.planalto.gov.br/CCIVIL_03/_Ato2011-2014/2014/ Decreto/D8243.htm>. Acesso em: 14 abr. 2014.

Brasil. (2014). Participação Social no Brasil: entre conquistas e desafios. Brasília: Secretaria-Geral da Presidência.

Cortes, S. M. V. (2011). As diferentes instituições participativas existentes nos municípios brasileiros. In: Roberto Rocha C. Pires. (Org.). Efetividade das instituições participativas no Brasil: estratégias de avaliação. Brasília: IPEA, p. 137-150

Fung, A. (2006). Receitas para esferas públicas: oito desenhos institucionais e suas conseqüências. In: COELHO, V. S. R. P. \& NOBRE, M. (orgs.). Participação e deliberação: teoria democrática e experiências institucionais no Brasil contemporâneo. São Paulo: Letras.

Geisel, Brigitte; Newton, Ken. (Ed.). (2012). Evaluating Democratic Innovations: Curing the Malaise. Londres: Routledge.

Heller, Patrick. (2001). Moving the State: The Politics of Democratic Decentralization in Kerala, South Africa, and Porto Alegre. Politics \& Society, Londres, v. 29, n. 1, p.131163, mar. Disponível em: <http://www.patrickheller.com/uploads/1/5/3/7/15377686/ moving_the_state.pdf >. Acesso em: 14 abr. 2016.

IPEA, Instituto de Pesquisa Econômica Aplicada; CGU, Controladoria-geral da União. (2015). Coleta OGU 2014: Relatório de Pesquisa. Brasília: Ipea. Disponível em: <http:// 
www.ouvidorias.gov.br/central-de-conteudos/biblioteca/relatorios/arquivos/coleta-ogu-2014-diagramado.pdf>. Acesso em: 15 abr. 2016.

Lavalle, A. Gurza. (2011). Após a participação: nota introdutória. Lua Nova (Impresso), v. 84, p. $13-24$.

Lavalle, A. Gurza. (2011b). Participação: valor, utilidade, efeitos e causa. In: Pires, Roberto. (Org.). Efetividade das instituições participativas no Brasil: Estratégias de avaliação. Brasília: IPEA, v. 7, p. 33-42.

Lavalle, A. Gurza; Isunza, E. (2011c). A trama da crítica democrática: da participação à representação e à accountability. Lua Nova (Impresso), v. 84, p. 95-140.

Lüchmann, L. H. H. O desenho institucional dos conselhos gestores. (2008). In: Lyra, R. P. (org.). Participação, democracia e segurança pública. A experiência brasileira. João Pessoa: UFPB.

Michels, Ank. (2011)Innovations in democratic governance: How does citizen participation contribute to a better democracy? In: International Review of Administrative Sciences, London, v. 2, n. 77, p.275-293, jun.

Milani, Carlos R. S. (2008). O princípio da participação social na gestão de políticas públicas locais: uma análise de experiências latino-americanas e européias. In: Revista de Administração Pública (Impresso), v. 42, p. 551-579.

Pires, Roberto; Vaz, Alexandre. (2012). Participação Social no Brasil como Método de Governo?: Um Mapeamento das "Interfaces Socioestatais" nos Programas Federais. Rio de Janeiro: Ipea. 60 p. Disponível em: <http://www.ipea.gov.br/portal/index.php?option $=$ com_content\&view $=$ article\&id=15116>. Acesso em: 11 abr. 2016.

Pogrebinschi, T. (2010). Participação como Representação: o impacto das conferências e dos conselhos nacionais na formulação e execução de políticas públicas (Relatório de pesquisa).

Pogrebinschi, Thamy; Tanscheit, Talita (2017). Moving Backwards: What Happened to Citizen Participation in Brazil?" In: Open Democracy/Democracia Abierta, November 30, 2017.

Porto de Oliveira, Osmany. (2012). Embaixadores do Orçamento Participativo: Um prelúdio à circulação internacional de um dispositivo de governança participativa. In: XXIInd World Congress of the International Political Science Association Reshaping Power, Shifting Boundaries. Mardid.

Saward, Michael. (2003). Democratic Innovation: Deliberation, Representation and Association. 2. ed. Abingdon: Taylor \& Francis E-library. 241 p. Disponível em: <https:// books.google.com.br/books?id=_PaCAgAAQBAJ\&printsec=frontcover\&hl=pt-BR\&source=gbs_ge_summary_r\&cad=0\# $\mathrm{v}=$ onepage\&q\&f;=false $>$. Acesso em: 03 abr. 2016. SGPR. (2011). Democracia Participativa: Nova relação do Estado com a Sociedade. 2. ed. Brasília: Secretaria-geral da Presidência da República. Disponível em: $<$ Nova relação do Estado com a Sociedade>. Acesso em: 13 abr. 2016. 
Silva, Enid Rocha Andrade. (2008). A Constituição Cidadã e a Institucionalização dos Espaços de Participação Social: Avanços e Desafios. In: ANFIP. (Org.). 20 anos da Constituição Cidadã: Avaliação e Desafios da Seguridade Social. 1ed. Brasília: ANFIP, p. 131-148.

Smith, Graham (Ed.). (2005). Beyond the Ballot: 57 Democratic Innovations from Around the World. London: Short Run Press,. 138 p. Disponível em: <https://core.ac.uk/download/files/34/30511.pdf>. Acesso em: 03 abr. 2016.

Smith, Graham. (2013). Democratic Innovations: Designing institutions for citizen participation. 3. ed. Cambridge: Cambridge University Press. Disponível em: <https:// books.google.co.in/books?hl=pt-BR\&lr;=\&id=gz8gAwAAQBAJ\&oi=fnd\&pg=PR8\&d$\mathrm{q}=$ democratic+innoivations\&ots=AUtCFoOPxS\&sig=SQYzxDbOeSSh_jFeYp7JL6XvX$\mathrm{h} 4 \# \mathrm{v}=$ onepage $\& \mathrm{q}=$ democratic innoivations $\& \mathrm{f}=\mathrm{false}>$. Acesso em: $14 \mathrm{abr} .2016$.

Souza, Clóvis. (2012). A que vieram as Conferências Nacionais? Uma análise dos objetivos dos processos realizados entre 2003 e 2010. Texto para Discussão 1718, Rio de Janeiro: Instituto de Pesquisa Econômica Aplicada - IPEA.

Teixeira, Ana Claudia C.; Souza, Clóvis Henrique L.; Lima, Paula Pompeu F. (2011). Arquitetura da participação no Brasil: uma leitura das representações políticas em espaços participativos nacionais. In: $35^{\circ}$ Encontro Anual da Anpocs, Caxambu/MG. Anais do $35^{\circ}$ Encontro Anual da Anpocs, de 24 a 28 de outubro de 2011.

Teixeira, Ana Claudia Chaves; Souza, Clóvis Henrique Leite; Lima, Paula Pompeu Fiuza. (2012). Arquitetura da participação no Brasil: uma leitura das representações políticas em espaços participativos nacionais. In: SOUTO, Anna Luiza Salles; PAZ, Rosangela Dias Oliveira. Novas lentes sobre a participação: utopias, agendas e desafios. São Paulo: Instituto Pólis. Cap. 3. p. 49-76.

Teixeira, Elenaldo. (2002). O local e o global: Limites e desafios da participação cidadã. $3^{\text {a }}$ ed. São Paulo: Cortez.

Vera, Ernesto Isunza; Lavalle, A. Gurza. (2012). Arquitetura da participação e controles democráticos no Brasil e no México. Novos Estudos CEBRAP (Impresso), v. 92, p. 105-121.

Wampler, Brian. (2012). Participation, Representation and Social Justice: Using Participatory Governance to Transform Representative Democracy. Polity, Boise University, v. 4, n. 44, p.666-682, Disponível em: <http://www.palgrave-journals.com/polity/ journal/v44/n4/full/pol201221a.html>. Acesso em: 03 abr. 2016. 
